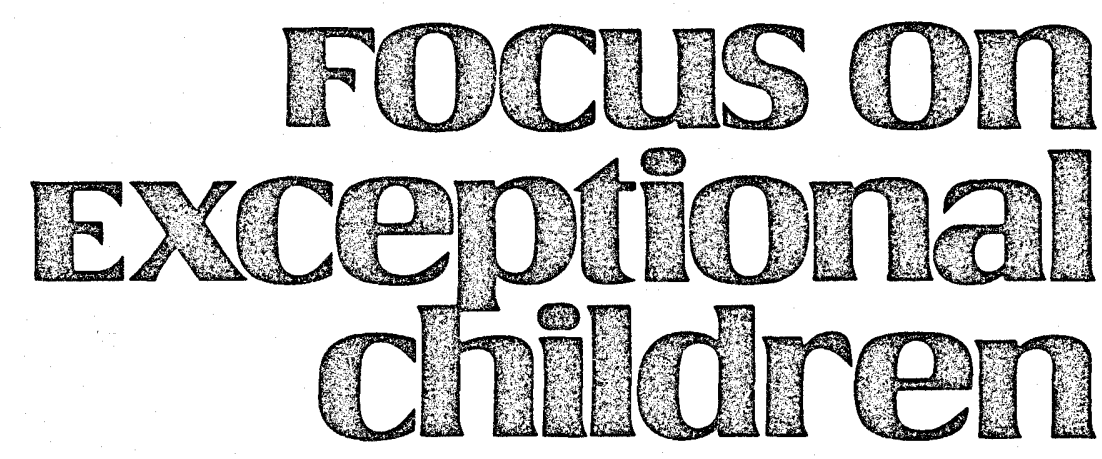

\title{
Teaching Reading to Learning Disabled Students: A Review of Research-Supported Procedures
}

\author{
Steve Graham and LeAnn A. Johnson
}

According to a model presented by Graham (1985), several factors can jointly or independently affect students' pursuits during learning. The most important of these is the student's entry behavior. The knowledge, skills, motivation, and so forth that students bring to the task can have a powerful impact on learning. A student's classroom peers also can have a direct influence (either positive or negative) on pupil pursuits. In cooperative learning situations, for example, peers can affect a student's pursuits through encouragement or by offering assistance. The student's teacher represents a third and powerful factor that can directly affect a pupil's pursuits. Teachers can (a) direct and support the actions of students through the external provisions of the lesson; (b) attempt to change the student's entry behaviors into more preferred ones; and (c) develop arrangements that promote mutual assistance among students during learning. Although Graham's model only briefly mentioned the role of the family, the actions of a child's parents or guardians also can have a strong impact on student learning.

This article focuses primarily on the effects of teacher behaviors and activities. First, it examines research-based teacher-directed activities administered before, during, or after the lesson (or any combination of these). Next, it presents procedures that teachers can use to change students' entry behaviors (both reading skills and strategic behaviors). Finally, it discusses teachers' arrangement of peers and the impact of the student's family.

\section{TEACHER ARRANGEMENT OF THE READING LESSON}

\section{Selecting Reading Material}

One of the most important tasks in designing an effective lesson is to select or construct materials that are attractive, well organized, and at the appropriate level (Graham, 1985). In reading, teachers and researchers commonly classify materials as being at the student's independent (easy to read), or instructional (difficult enough to require teacher

Steve Graham is an Associate Professor and LeAnn Johnson is a Doctoral Candidate, both in the Special Education Department at the University of Maryland.

Most of the studies included in this review were conducted with students in elementary or secondary schools who had been identified as LD by the researchers or the participating school system. A few studies were included that examined the effects of specific teaching procedures with disabled readers of average intelligence; these students had not been identified as LD. Not included in this review were studies examining the effects of available commercial programs (e.g., Distar), summer school instruction, or modality/learning style adaptations. Also not included were studies investigating the effects of indirect training (e.g., problem-solving training) on reading performance. The instructional procedures reviewed were presented within the framework of a model of the teaching-learning process proposed by Graham (1985). The central tenet of this model is that academic learning is a direct result of students' activities and pursuits. 
assistance), or frustrational (too difficult) level. Researchers have provided convincing evidence on the value of assigning materials that are at an appropriate level for LD students (Armstrong, 1983; Gickling \& Armstrong, 1978). For example, when Gickling and Armstrong assigned instructionallevel material to students functioning at the frustrational level on classroom reading assignments, the students' comprehension performance, on-task behavior, and task completion improved. Techniques that teachers can use to determine if materials are at a student's independent, instructional, or frustrational level have been presented by Graham (1983).

When selecting materials, teachers should be aware that the format or structure used to present information can affect a student's comprehension. Gold and Fleisher (1986) found that deductively organized text (main idea in the first sentence with details following) was easier for LD students to recall than inductively organized text (main idea presented later in the paragraph or left to be inferred). Because most reading materials contain both of these formats (as well as others), providing instruction on the organizing principles underlying common text structures may be advisable.

\section{FOCus on
Exceptional children}

FOCUS ON EXCEPTIONAL CHILDREN (ISSNO015-511X) (USPS 203-360) is published monthly except June, July, and August as a service to teachers, special educators, curriculum specialists, administrators, and those concerned with the special education of exceptional children. This publication is annotated and indexed by the ERIC Clearinghouse on Handicapped and Gifted Children for publication in the monthly Current Index to Journals in Education (CIJE) and the quarterly index, Exceptional Children Education Resources (ECER). It is also available in microform from Xerox University Microfilms, Ann Arbor, MI. Subscription rates: Individuals, \$24 per year; institutions, $\$ 30$ per year. Copyright (C) 1989, Love Publishing Company. All rights reserved. Reproduction in whole or part without written permission is prohibited. Printed in the United States of America. Second class postage is paid at Denver, Colorado.

POSTMASTER: Send address changes to:

$$
\begin{gathered}
\text { Love Publishing Company } \\
\text { Executive and Editorial Office } \\
1777 \text { South Bellaire Street } \\
\text { Denver, Colorado } 80222 \\
\text { Telephone (303) } 757-2579
\end{gathered}
$$

EDITORIAL BOARD

Edward L. Mẻyen

University of Kansas

Richard J. Whelan

University of Kansas Medical Center

Stanley F. Love Publisher

Glenn A. Vergason Georgia State University

Carolyn Acheson Senior Editor
When selecting reading materials, another important factor involves illustrations. Although illustrations can make materials more attractive, and thus more interesting, some experts have argued that illustrations can have a detrimental effect on LD students' reading, particularly if students have poorly developed basic reading skills or if the pictures present ambiguous or inaccurate information (cf. Harber, 1983; Rose \& Robinson, 1984; Rose, 1986). The most important questions regarding illustrations, however, may center on the quality of the picture. Mastropieri, Scruggs, and Levin (1987) reported that different types of illustrations are not equally beneficial; pictures containing information relevant to the desired outcome facilitated reading performance.

After reading materials have been selected, teachers also can consider how the materials should be displayed. For instance, reading materials can be presented directly on a computer monitor instead of the traditional format of the printed page. The use of computer-displayed text, over a short time period, does not appear to have a negative effect on LD students' comprehension processing, strategy use, or on-task behavior (Keene \& Davey, 1987).

The display of text can be modified further by segmenting the material into smaller parts. O'Shea and Sindelar (1983) found that segmenting paragraphs into sequentially organized phrases improved the comprehension of poor readers. Although text segmentation is a time-consuming process, it may help to promote phrase reading and simplify the syntax of complex sentences, allowing the reader to concentrate on the relationship among phrases.

\section{Teacher Activities Prior to Reading}

Prior to having LD students read assigned passages, a teacher can use a number of activities or procedures to promote comprehension, fluency, accuracy, or a combination of these. Such activities may help students by directing or supporting what they do during the process of reading (Graham, 1985).

\section{Setting Goals}

Setting and selecting goals are central to the process of reading. Although teachers typically assume that the goal of reading is to construct meaning, students' goals actually may be to say the words right or answer the questions (Palinscar \& Brown, 1988). Thus, identification of the purpose for reading by the student and the teacher is a commonly recommended instructional practice.

Research with LD students has concentrated on teacherconstructed goals; teachers set the purpose for reading and convey the goal through either a verbal or a written prompt. In a study by Pflaum, Pascarella, Auer, Augustyn, and Boswick (1982), a traditional purpose-setting aid ("This is a story about anteaters. You are going to read about how 
anteaters get food to eat, about their size, and about where they live," p. 111) was not effective in improving young LD students' recall. Similarly, O'Shea, Sindelar, and O'Shea (1987) found that instructing students to read quickly and correctly had no effect on LD students' fluency. They did find, however, that a cue to "remember as much as you can about the story" resulted in improved recall of story material.

In addition, Roberts and Smith (1980) found that giving LD students a specific purpose for reading (read more words correctly, reduce number of reading errors, or answer more comprehension questions), a strategy for meeting the assigned purpose, and reinforcement for accomplishing the goal resulted in improvement on a measure directly related to the assigned purpose. Finally, Wong, Wong, and Le Mare (1982) reported that LD students who were told explicitly why they were reading a passage (to take a test) performed significantly better on a comprehension test than did a control group of students who were not informed of the purpose of reading.

Another purpose-setting procedure used with LD students is the presentation of content-related questions prior to reading. Questions of this nature should help students focus attention on important text material. Bergerud, Lovitt, and Horton (1988) examined the effectiveness of assigning LD adolescents specific study guide questions to be answered while studying life science material. Although this particular technique was not effective, use of this general procedure should be investigated more fully. The effects of studentgenerated goals also should be examined.

\section{Making Predictions}

Asking students to make predictions about upcoming content requires them to draw and test inferences about the text to be read (Palinscar \& Brown, 1984). Prior to reading a story, Sachs (1984b) asked students questions that required them to think about the goals and plans of the protagonist. These included: What is the main character in this story likely to want? How is the main character going to accomplish the goals? What do you think the main character should do? This procedure had a positive effect on LD students' comprehension of the story.

\section{Activating Prior Knowledge}

Helping poor readers activate relevant prior knowledge before reading should have a positive effect on reading performance (Holmes, 1983). Support for this proposition has been provided by McCormick and Hill (1984). They had poor readers write and "weave" together answers to teacherprepared questions designed to help them relate their own background knowledge to the topic of the story and to make predictions about the story. Students were instructed further that during reading they should "combine knowledge they already have in their brains with predictions about what will occur in the story" (p. 222). The procedure was more effective than traditional reading instruction in improving comprehension. On the other hand, Pflaum et al. (1982) did not find that asking questions designed to activate prior knowledge, coupled with a cue to consider if anything new was learned, was effective in increasing the amount of information LD students recalled.

\section{Using Advanced Organizers}

Advanced organizers that provide an overview of the assigned passage prior to reading appear to offer an effective procedure for increasing comprehension. Idol-Maestas (1985) gave students the following prompts to be used with basal stories prior to reading: (1) What is the title? Does it give a clue as to what the story is about? (2) Look through each page of the story. Skim for clues. (3) Look for important words. Talk about what they mean. (4) Look for hard words. Practice saying them and talk about what they mean. (5) What is the setting of the story? When does it take place? Where did it take place? When directed to use these prompts, LD students' performance in answering factual, sequential, and inferential questions improved.

Darch and Gersten (1986) have developed an advanced organizer to be used with science and social studies curricula. Prior to reading, the teacher presents an outline consisting of the important facts and concepts included in the passage, as well as relationships among the various components. LD students receiving this outline scored higher on a comprehension measure than did those receiving traditionally oriented instruction.

\section{Previewing}

Teachers frequently ask LD students to read assigned materials outloud (Leinhardt, Zigmond, \& Cooley, 1981). For poor readers, this can be frustrating, as they may not be very fluent or may make a lot of oral reading errors (cf. Graham, 1980). Previewing as a means for improving oral reading behavior involves exposing the student to a reading passage prior to required oral reading.

A series of studies by Rose reported the following findings: (1) allowing LD students to preview a passage silently prior to oral reading resulted in higher rates of word accuracy than a no-previewing condition (Rose, 1984; Rose \& Sherry, 1984); (2) having LD students listen to a prerecorded tape of the material while following along silently prior to oral reading yielded higher rates of word accuracy than no previewing (Rose \& Beattie, 1986); and (3) directing students to follow along silently while the teacher read the passage aloud prior to oral reading was more effective than no previewing or either listening or silent previewing (Rose, 1984; Rose \& Beattie, 1986; Rose \& Sherry, 1984). 


\section{Introducing Key Concepts and New Vocabulary}

Another common prereading activity is to introduce and discuss key concepts and any new vocabulary presented in the reading material. Because students often encounter new words and ideas in assigned passages, the introduction of key concepts and words prior to reading is generally believed to facilitate comprehension.

In terms of prereading activities involving key ideas, Sachs $(1983$, 1984a) found that analyzing the main concept of a passage prior to reading had a positive effect on $L D$ students' comprehension and oral reading speed and accuracy. The steps included: (1) the teacher writing out the central concept of the passage, (2) the teacher and students generating a list of examples and nonexamples of the concept, and (3) the student generating a definition of the concept based upon the examples and nonexamples.

Bos and her colleagues (Anders, Bos, \& Filip, 1984; Bos, Anders, Filip, \& Jaffee, 1985) have examined the effectiveness of semantic feature analysis, an activity that concentrates on both key ideas and vocabulary. With this procedure, the teacher first introduces a chart listing the major concepts presented in the passage across the top and the related vocabulary down the side. Each of the major concepts and vocabulary items then are briefly explained. Students rate each vocabulary item in relation to each concept as having a positive, a negative, or an unrelated relationship. Next, students read the passage to verify their rating and to clarify any questionable relationships. The procedure has had a positive impact on LD adolescents' recall of concepts and understanding of social studies text.

When only new vocabulary items are introduced, the results have not been as promising. Experiments conducted with LD students in the upper elementary grades have shown that learning the meaning of unfamiliar words in a story has not improved passage comprehension; these results were consistent across different methods of vocabulary instruction (Pany \& Jenkins, 1978; Pany, Jenkins, \& Schreck, 1982). Nevertheless, method of vocabulary instruction did have a differential effect on the learning of word meanings. The most effective procedure involved pairing an unknown word with either a definition or a synonym and a sentence containing the target item, followed by considerable practice in producing the correct definition or synonym. Simply telling students the meaning of the word after reading it in context had a positive, although weaker, effect on learning new vocabulary.

\section{A Recap}

In concluding this discussion, two comments seem to be in order. First, a broad combination of teacher-directed ac- tivities or procedures often has a powerful effect on pupil pursuits during learning (Graham, 1985). Thus, a sensible combination of several of the prereading activities presented could prove advantageous. Second, more attention has to be given to what students internalize as a result of teacher assistance immediately prior to reading a selected passage (or, for that matter, during or after reading).

\section{Teacher Activities During and After Reading}

Specific activities that teachers can institute during and after reading to affect $L D$ students' performance on assigned materials are described next.

\section{Reinforcing Specific Reading Behaviors}

Although the use of contingent reinforcement is a popular and effective intervention (Harris, Prellor, \& Graham, 1988), relatively few studies have examined its use in improving LD students' reading performance. A notable exception was a study by Jenkins, Barksdale, and Clinton (1978). They found that administering reinforcement to poor readers contingent upon either their comprehension or oral reading performances resulted in improvement in answering passage questions and oral reading accuracy, respectively.

In a study by Swanson (1981), LD students self-recorded their reading behavior and subsequently were reinforced contingent upon their performance. The combination of selfrecording and reinforcement resulted in improvements in comprehension, silent reading rate, and oral reading accuracy when each was targeted for intervention. It is important to note that improvements in oral and silent reading behaviors had only marginal effects on comprehension. Similar results were reported by Jenkins et al. (1978).

\section{Requiring Repeated Readings}

A simple means for improving LD students' reading is to have them read the same passage more than once. O'Shea et al. (1987) found that having LD students read a passage three times resulted in better comprehension and more fluent reading as compared to a single reading.

\section{Correcting Errors During Oral Reading}

Considerable research has examined the effectiveness of various teacher-directed procedures for correcting LD students' errors during oral reading. Probably the most common method of teacher correction is to supply the correct response for the unknown word or error and then to have the student repeat the correct response. Although word supply has been found to be more effective in increasing correct oral reading than no correction procedures or a phonics correction proce- 
dure (cf. Jenkins \& Larson, 1979; Rose, McEntire, \& Dowdy, 1982), the effects generally have not been very powerful. As a result, researchers have examined how word supply might be augmented to make it more effective.

The most popular augmentation has been to combine word supply with drill; the correct response for each error is practiced following completion of the passage. In comparison to word supply, this procedure has proven to be effective in improving LD students' performance on word recognition in isolation and, to a lesser extent, in context (Jenkins \& Larson, 1979; Jenkins, Larson, \& Fleisher, 1983; O'Shea, Munson, \& O'Shea, 1984; Rosenberg, 1986). The procedure, however, has only a small or marginal effect on comprehension (Fleisher \& Jenkins, 1983; Jenkins et al., 1983). Other attempts to improve on word supply have included rereading the sentence after an error correction, reviewing all corrected errors at the end of the page, or telling the student the word meaning as part of the correction procedure. Each of these turned out to be only slightly better than word supply in improving LD students' word recognition performance (Jenkins \& Larson, 1979).

Researchers also have tried to improve the word supply plus drill procedure. Fleisher and Jenkins (1983) found that supplementing word supply plus drill with comprehension questions at the end of each page did not result in an incremental improvement in LD students' reading. Rosenberg (1986) reported that modifying the drill procedure to phonics practice (sounding out) of the missed word did not result in improved oral reading behavior. In contrast, O'Shea et al. (1984) indicated that practicing the missed word within the context of the phrase in which it appeared was more successful in improving contextual reading than was flashcard practice.

Frequent teacher interruptions during oral reading may be counter-productive to the goal of self-reliant reading (Shake, 1986). They may interrupt the reader's line of thought and perpetuate an over-reliance on the teacher. We, therefore, recommend that teachers' corrections center primarily on miscues that disrupt meaning.

\section{Inserting Questions into Text}

Inserting questions into text provides a mechanism for directing students' attention to specific information and may promote retention of important information. In a study by Wong (1979), LD students were asked a single question just prior to reading each paragraph in a story. Students who were asked questions recalled more of the story than students who were not given questions.

In another study by Wong (1980), questions were inserted immediately after specific text material. Because the questions resulted in improved comprehension, they may have acted as prompts to remind LD students to apply constructive processing strategies.

\section{Asking Post-Comprehension Questions}

Asking students comprehension questions immediately following reading and encouraging them to "look back" in the text to locate the correct answers to missed questions constitute a common practice. Davey (1987), for example, asked poor readers to answer post-passage questions under two conditions: text-lookbacks allowed and not allowed. Poor readers were able to correctly answer more questions requiring a written response when lookbacks were permitted; lookbacks did not affect their performance on multiplechoice questions.

\section{Promoting Text Summarization}

Summarizing text consistently has been shown to result in improved recall of written content (Pressley, Johnson, Symons, McGoldrick, \& Kurita, in press), even when students are directed to use very simple forms of summarization. For instance, Jenkins, Heliotis, Haynes, and Beck (1986) inserted a lined space after each paragraph of a story and directed LD students to write a brief sentence summarizing each paragraph after reading it. The restatement condition resulted in superior comprehension performance in comparison to two control conditions.

\section{Focusing Students' Attention on Text Structure}

Reading material such as conventional stories often share a general structure (Graham, Harris, \& Sawyer, 1987). Idol (1987b; Idol \& Croll, 1987) has investigated using text structure to improve LD students' comprehension. She had LD students complete a chart during or after reading, or both; the chart contained boxes for information on the setting, problem, goal, action, and outcome of the story. Use of the chart resulted in improved comprehension, and the students appeared to have internalized some components of the mapping procedure because most of them maintained acceptable levels of comprehension after the chart was discontinued.

\section{Focusing Students' Attention on Important Information Using Charts or Graphics}

Idol (1987a) also investigated the use of a mapping procedure with content area material. High school students who were poor readers were taught to complete a chart designed to accompany a history text; the chart contained boxes for information on important events, main ideas of the lesson, other viewpoints/opinions, reader's conclusion, and rele- 
vance to today. Use of the chart resulted in improved performance on the content material, and these gains generally were maintained once the chart no longer was used.

Bergerud et al. (1988) examined the use of graphics to improve LD students' retention of information in science text. The graphs contained a diagram (e.g., the heart) with blanks for important information (size, location, etc.). Students read the content passage, completed the graph, and discussed the answers with the teacher. In comparison to self-study or the use of a study guide, graphics resulted in greater content retention.

\section{Circumventing Process Demands}

At the secondary level, reading is primarily a tool for acquiring content area information. Although many LD students have the cognitive capability to understand the information presented in secondary text, their poor reading skills often make this task difficult (Deshler \& Graham, 1980). An instructional alternative is to use teacher-directed activities designed to circumvent the processing demands inherent in reading. Alternatives include rewriting texts so that they are simpler, tape-recording textual material, or presenting text through the use of charts or other adaptations. The last two procedures have been investigated with $L D$ students.

For chapter-length materials, verbatim text recordings used with or without the accompanying text do not appear to significantly affect LD adolescents' learning of chapter content (Schumaker, Deshler, \& Denton, 1984; Torgesen, Dahlem, \& Greenstein, 1987). Combining text recording with text study procedures, however, appears to be effective. Torgesen et al. (1987) found that coupling a verbatim recording and a highlighted text with a worksheet containing content questions resulted in improved performance. In addition, Schumaker et al. (1984) reported that verbatim text recording coupled with a highlighted text, worksheet activities, and the learning of a specific study strategy improved scores on chapter tests.

Finally, Darch and Carnine (1986) examined the effects of presenting information contained in content area text via visual spatial displays. The displays were designed so that relationships of content in the chapters could be presented visually with pictures and words. The display was first presented on an overhead projector, and the teacher described the ideas on the display and their interrelationships. Next students reviewed the material while working in small cooperative groups. In comparison to traditional instruction, the use of visual spatial displays resulted in greater learning of content.

\section{IMPROVING STUDENTS' READING BEHAVIORS}

Teacher activities just prior, during, or immediately after reading are designed to assist the student in reading and comprehending assigned materials. Such external provisions often produce immediate effects, but they are analogous to a "heart pacer" in that the teacher's manipulation does some or even most of the work for the student (cf. Graham, 1985). This is not meant to imply that the act of reading alone or in combination with such provisions does not result in new learning; reading and the effects of the external provisions of the lesson result in acquisition of new information and skills, as demonstrated by the studies reviewed in previous sections. Nevertheless, teachers of LD students often have to take a more direct course of action to change existing reading behaviors into more preferred ones. This involves altering students' entry behaviors so that their reading skills progressively improve and they become less reliant on teacher manipulations. Current research has concentrated primarily on improving LD students' basic reading skills and their strategic reading behaviors.

\section{Reading Skills}

Guthrie and Tyler (1978) recommend that instruction for poor readers should be directed at simultaneously improving as many deficient cognitive processes (as defined by underdeveloped skills) as necessary for reading to improve. As a group, LD students have difficulty with a wide variety of reading skills, including word recognition and decoding (cf. Manis, 1985), as well as comprehension (Hansen, 1978). We further agree with Guthrie and Tyler's recommendation that reading skills be taught directly and that sufficient instructional time be allocated for their mastery.

\section{Word Recognition Instruction}

Word recognition is a central and recurring part of reading. If students do not learn to recognize quickly and effortlessly the vast majority of words they will encounter in reading, comprehension processes are at risk (Perfetti, 1986). Probably the most common means by which LD teachers have tried to bolster students' word recognition skills is by improving their sight vocabulary. Research with $L D$ students has primarily examined the effectiveness of procedures for teaching sight vocabulary presented in a list format. One of the more relevant findings is that instructional effectiveness can be increased through a judicious combination of teaching procedures.

For instance, Thorpe and Borden (1985), reported that the addition of either praise or letter tracing improved the effectiveness of a word study procedure that involved saying the word, sounding it out, and saying it again. Other researchers have indicated that learning of words can be facilitated through the use of games such as Bingo (Kirby, Holborn, \& Bushby, 1981) or by pairing the target word with a picture (Jorm, 1977; Knowlton, 1980). The use of pictures may be 
advisable, however, only when used with high imagery words (cf. Jorm, 1977) or faded over trials (cf. Knowlton, 1980). Finally, Freeman and McLaughlin (1984) found that reading target words while listening to them on a tape recorder (presented at 80 words per minute) decreased LD students' word errors and increased correct rate of responding.

It is surprising that researchers have not placed more emphasis on having LD students apply sight word skills in context. Allington (1978) reported that the errors poor readers make in isolation are not predictive of errors they make in context, and vice versa. A study that did follow sight word training in isolation with contextual practice was conducted by Bryant, Fayne, and Gettinger (1982). They had LD students master small sets of words using flashcard training coupled with practice in discriminating the target words from similar nonsense words. The target words then were practiced in phrases, sentences, and stories. The procedures improved students' skills in recognizing words in isolation; unfortunately, performance in context was not examined.

Future research should examine what sight words should be taught to LD students. Frequency, meaningfulness, concreteness, and phonetic regularity represent some of the viable attributes in selecting words to be learned. Furthermore, more attention should be devoted to developing automaticity, particularly in applying new sight words in context.

Other procedures for improving word recognition skills include: (a) instruction in the use of the reading context as an aid in recognizing and determining the meaning of unknown words, and (b) repeated readings of passages as a means for reducing word recognition errors and promoting fluency. Dahl (1979) reported that poor readers who received training in the use of context or repeated reading practice read with greater word recognition and fluency than students who received flashcard instruction on sight words. Moreover, incremental effects were obtained by providing students with both types of training. Rashotte and Torgesen (1985) have sounded a note of caution regarding repeated reading practice, however. They found that repeated reading was no more effective than nonrepetitive reading if the passages used in repeated reading shared few words in common.

\section{Decoding Instruction}

An important goal for reading instruction is to help students develop a flexible and efficient decoding process. In addition to being able to recognize common words without effort, readers need a solid backup system for decoding words that are unknown (Perfetti, 1986). Although good readers often acquire decoding skills through exposure to printed words, poor readers are not as adept in discovering, without direct instruction, how our language works (Gaskins et al., 1988). Poor readers need to learn about alphabetic principles, specific orthographic patterns of the writing system, and specific mapping of print to speech; "this conclusion has been reached many times by thoughtful researchers in reading instruction" (Perfetti, 1986, p. 19).

One approach that researchers have used to improve LD students' decoding skills is to teach essential components of the decoding process. Bradley and Bryant (1985) found that training in phonological awareness resulted in improved reading achievement for young children with low categorization test scores. Instruction that involved arranging pictures of words according to their shared sound characteristics (beginning, middle, or ending sounds) plus forming words using plastic letters was particularly effective. Fayne and Bryant (1981) reported that direct instruction on a decoding strategy that emphasized clustering and blending the first two letters (CV) with the final letter (C) was more effective than several other alternative strategies, including letter-byletter decoding. Henderson and Shores (1982) noted that training LD students to attend to suffixes while reading orally resulted in improved comprehension and reading fluency.

Other researchers have developed and field-tested instructional programs designed to teach a variety of decoding skills. Williams (1980) developed a program that provides instruction in syllabication, phoneme analyses and blending, letter-sound correspondences, and decoding various spelling patterns (CVC, CVCC, etc.). In addition, skills to be mastered initially were presented in context, and students were provided opportunities following instruction to apply target skills in context. LD students who participated in this program evidenced improvements in decoding skills and strategies.

A final decoding program that merits attention was developed at Benchmark School (Gaskins et al., 1988). It includes daily lessons that supplement the students' basal reading program. Decoding skills are taught using explicit modeling, and lessons are fast-paced and game-like. Students are informed why each targeted skill is important, how to do it, and when to use it. Preliminary results indicate that the program improves decoding performance.

\section{Vocabulary Instruction}

Students' vocabulary knowledge and their reading comprehension have a strong relationship (Pany \& Jenkins, 1978). As a result, many educators have promoted the systematic and extensive development of students' vocabulary in the belief that such growth will have a reciprocal effect on reading comprehension (Pany et al., 1982). Surprisingly, few investigations on vocabulary instruction have been done with LD students. A notable exception is Mastropieri, Scruggs, and Levin's (1985) research. They have taught 
both general and specialized vocabulary to LD students using a mnemonic technique, the keyword method. To illustrate, a student is taught a keyword (doll) for a target word (dahlia-a flower) and then shown a picture depicting the keyword interacting with its corresponding meaning (doll sniffing a flower). The student is instructed to use the keyword and the picture to think of the meaning of the vocabulary item.

Although vocabulary instruction using the keyword method has proven to be effective for learning word meanings (cf. Condus, Marshall, \& Miller, 1986; Mastropieri et al., 1985), questions regarding its acceptability remain. Developing keywords and interactive pictures is time-consuming, possibly precluding widespread use by teachers. These roadblocks can be bridged by having students develop the interactive pictures (Mastropieri, Scruggs, Levin, Gaffney, \& McLoone, 1985) or through marketing commercial materials using this methodology.

To conclude this discussion of vocabulary instruction, reiterating some general recommendations of McKeown and Beck (1988) may be helpful. Effective teaching of vocabulary involves both definitional and contextual information, high frequency of encounters with each word, multiple exposures to target words in different contexts, and encouraging students to extend their use of new words outside the classroom. McKeown and Beck further recommend that a vocabulary program include the following two components: (1) introduction to a lot of words simply by establishing an association to a definition or synonym, and (2) rich instruction, as described previously, on a smaller set of words (e.g., words important to central ideas in a basal reader).

\section{Comprehension Instruction}

Another means for improving LD students' reading is to provide comprehension instruction. Only a few studies have provided comprehension training, but results from these investigations have been encouraging. White, Pascarella, and Pflaum (1981) improved LD students' reading comprehension by providing practice in arranging word cards into sentences. Students learned to construct sentences by first locating the sentence verb and then using a series of questions (who, what, when, where, why, and how) as cues for grouping other words around the verb. Students also noted if each unit was included, complete, and made sense. Williams (1986) tested an instructional program that trained identification of the general topic, the specific topic, and anomalous sentences in short paragraphs. Training resulted in improved performance on main idea comprehension. Finally, Darch and Kameenui (1987) found that direct instruction in using specific rules and strategies to detect instances of faulty arguments improved LD students' critical reading skills.

\section{Strategic Reading Behaviors}

Personal qualities such as attitudes and the strategies students use to learn can be altered so they exert a positive influence on performance (Graham, 1985). As Pressley et al. (in press) noted, reading performance can be improved by teaching students to independently use strategies involving summarization, mental imagery, self-questioning, question answering, and so forth. LD students appear to be prime candidates for strategy instruction, as their strategic reading behavior appears to be inefficient and inflexible (Wong, 1982).

Various self-questioning strategies have been found to be effective in improving LD students' reading comprehension:

- Stopping while reading to check to see if the material being read is understood (Graves, 1986)

- Generating several questions to ask an imaginary friend after reading the assigned text (Chan \& Cole, 1986)

- Asking and answering "WH" questions (who, what, when, where, why) while reading; the student marks each answer so that the type of question asked is identified (Clark, Deshler, Schumaker, Alley, \& Warner, 1984)

- Asking and answering questions related to the schematic structure of the text; e.g., "What does the main character want to do?" (Carnine \& Kinder, 1985; Short \& Ryan, 1984)

- Reading a question at the end of the passage, formulating a tentative answer, and confirming the answer based on text information (Holmes, 1985)

- Clarifying the purpose for reading, asking and answering questions about main ideas, and successively collating answers to new questions with answers to previous questions (Wong \& Jones, 1982)

Other strategies that have been helpful in improving LD students' reading comprehension include summarizing (Jenkins, Heliotis, Stein, \& Haynes, 1987; Rose, Cundick, \& Higbee, 1983) and visual imagery (Rose et al., 1983; Clark et al., 1984). To illustrate, Jenkins et al. taught LD students to summarize by answering two questions: Who? and What's happening? Training resulted in an increase in the number of comprehension questions answered correctly. Similarly, Clark et al. (1984) found that training LD students to form and evaluate visual images for successive sentences resulted in improved performance in answering comprehension questions. Finally, Carnine and Kinder (1985) noted that summarizing and visual imagery can be used together; making and describing successive visual images of the reading material followed by summarizing the entire passage resulted in improved comprehension.

LD students' performance on both basal and content area materials has been improved by teaching them specific study 
strategies. Alexander (1985) found that teaching LD students a modified version of the SQ3R technique resulted in improved recall. Similar results with a particularly complex modification of the SQ3R procedures were noted by Schumaker, Deshler, Alley, Warner, and Denton (1982). Chan and Cole (1986) reported that comprehension performance was improved by using the traditional study strategy of underlining; students underlined interesting words after reading the passage. In a seminal investigation by Palinscar and Brown (1984), LD adolescents' performance in content area materials improved following training in four study activities: summarization, questioning, clarifying, and predicting.

A final strategy that we would like to highlight was developed by Pflaum and Pascarella (1980). They taught LD students rules for self-correcting their oral reading errors. When self-correcting, students learned to first focus on context cues and then graphic cues, and to ask if the correction helped the sentence make sense. Training in the strategy resulted in positive changes in reading behaviors, especially for students reading at second grade level or higher.

Though the use of strategy training to improve LD students' reading has been promising, questions regarding generalization and maintenance remain. Researchers also should direct more attention to validation of instructional manipulations, confirmation of mediating responses, establishment of social validity, and efficacy of various treatment components. With regard to the latter, multicomponent instructional methods for teaching strategic behaviors have been described by Graham et al. (1987) and Palinscar and Brown (1984).

\section{IMPACT OF PEERS ON PUPIL PURSUITS}

LD students' immediate peers and other students often represent an untapped resource that can be used to affect pupil pursuits during reading. Peers can be trained to fulfill a variety of roles. These include administering prereading activities, providing assistance during and after reading, and teaching basic reading skills.

In terms of prereading activities, Salend and Nowak (1988) investigated the effects of having an LD student who was a more proficient reader orally preview a passage with an LD student who was a less proficient reader. While the previewer read a passage aloud, the other student listened and followed along using a photocopy of the passage. In comparison to silent previewing, peer-previewing resulted in a marked decrease in the number of oral reading errors committed by less proficient LD readers.

Peers also have been trained to provide assistance to LD students as they read. This generally has involved providing reinforcement for correct reading, feedback on the type of error that has occurred, correction of the error, practice reading the miscue successfully, or some combination of those (Jenkins, Mayhall, Peschka, \& Jenkins, 1974; Sindelar, 1982; Trovato \& Bucher, 1980; Willis, Morris, \& Crowder, 1972). Usually, such procedures have had a positive impact on LD students' oral reading.

An interesting study was conducted by Fleisher and Jenkins (1978). Prior to reading, cross-age tutors had LD students practice isolated letter sounds followed by isolated practice of unknown words from the target reading material. Word practice consisted of the tutor directing the LD child to sound out the unknown word. When necessary, the tutor modeled the sounding-out procedure and had the tutee repeat the word. The prereading activities were followed by having the LD student orally read the target passage to the tutor. If the student made an error, the sounding-out and modeling procedure was used. The peer-directed activities resulted in an increase in the number of words read correctly in both isolation and context.

Research also has examined using tutors to teach specific reading skills. Most of this instruction has involved learning common reading words via flashcard instruction (Jenkins et al., 1974; Sindelar, 1982). Overall, the use of peers to teach sight vocabulary has yielded positive effects (Chiang, Thorpe, \& Darch, 1980; Epstein, 1978; Jenkins et al., 1974).

A study of final interest was conducted by Sindelar (1982). Normal students taught LD students how to successfully predict upcoming words in both spoken and written context. Tutoring in word prediction was more successful in promoting comprehension than was having peers teach sight vocabulary. Also, tutors were as successful as teachers in administering training.

Prior to concluding this section, three caveats are in order. First, successful tutoring requires well trained tutors and close monitoring of the process. Second, we believe that tutors can learn to teach specific reading strategies to LD students. For example, in a study by Miller, Miller, and Rosen (1988), a modified form of reciprocal teaching was implemented in which "normal" students initially acted as the "teacher" to explain and model a variety of comprehension strategies. Third, cooperative learning arrangements represent a potentially powerful mechanism for having peers assist $\mathrm{LD}$ students during reading activities (see Slavin, Stevens, \& Madden, 1988).

\section{FAMILY IMPACT ON PUPIL PURSUITS}

A student's family can have a powerful impact on a child's performance in school (Graue, Weinstein, \& Walberg, 1983). Although extensive research examining the effect of the family on LD students' reading is lacking, some evidence suggests that parents can successfully deliver instruction and also can serve to reinforce their child's performance on school tasks. In terms of instruction, Gang and Poche (1982) 
taught parents of poor readers how to teach sounding and blending skills to their child when using a commercial reading program. Following 5 hours of group training, the parents were able to successfully apply the instructional procedures, and the instruction had a positive impact on reading performance.

With regard to delivering reinforcement, Trovato and Bucher (1980) asked parents to help select reinforcers and then administer reinforcement contingent on their child's performance during peer tutoring. Although both reading accuracy and comprehension were significantly increased by peer tutoring, home-based reinforcement doubled the observed increases.

In addition to administering reinforcement and teaching basic skills, a variety of parent-directed activities should have a positive impact on the LD child. These include reading together, modeling desirable reading behaviors, and monitoring (assisting when necessary) in the completion of homework.

\section{CONCLUDING COMMENTS}

The last 10 years have witnessed a substantial increase in instructional reading research conducted with LD students. Nonetheless, the current research base provides a somewhat narrow and tentative foundation for drawing instructional recommendations. We hope that the next decade will see an increase in research with LD students on promoting a positive attitude and the desire to read, developing effective and efficient systems for decoding, improving performance in content area materials, facilitating generalization and maintenance of learned skills and strategies, and examining what is internalized as a result of reading instruction.

\section{REFERENCES}

Alexander, D. F. (1985). The effect of study skill training on learning disabled students' retelling of expository material. Journal of Applied Behavior Analysis, 18, 263-267.

Allington, R. L. (1978). Word identification abilities of severely disabled readers: A comparison in isolation and context. Journal of Reading Behavior, 10, 409-416.

Anders, P. L., Bos, C. S., \& Filip, D. (1984). Effect of semantic feature analysis on the reading comprehension of learning-disabled students. In J. Niles (Ed.), Changing perspectives on research in reading/language processing and instruction (33rd yearbook of the National Reading Conference) (pp. 162-166). Rochester, NY: National Reading Conference.

Armstrong, S. W. (1983). The effects of material difficulty upon learning disabled children's oral reading and reading comprehension. Learning Disability Quarterly, 6, 339-348.

Bergerud, D., Lovitt, T. C., \& Horton, S. (1988). The effectiveness of textbook adaptations in life sciences for high school students with learning disabilities. Journal of Learning Disabilities, 21, 70-76.

Bos, C. S., Anders, P. L., Filip, D., \& Jaffee, L. E. (1985). Semantic feature analysis and long-term learning. In J. Niles (Ed.), Issues in literacy: A research perspective (34th yearbook of the National Reading Conference) (pp. 42-47). Rochester, NY: National Reading Conference.
Bradley, L., \& Bryant, P. (1985). Rhyme and reason in reading and spelling. Ann Arbor: University of Michigan Press.

Bryant, N. D., Fayne, H. R., \& Gettinger, M. (1982). Applying the mastery learning model to sight word instruction for disabled readers. Journal of Experimental Education, 51, 116-121.

Carnine, D., \& Kinder, D. (1985). Teaching low-performing students to apply generative and schema strategies to narrative and expository material. Remedial \& Special Education, 6, 20-30.

Chan, L. K. S., \& Cole, P. G. (1986). The effects of comprehension monitoring training on the reading competence of learning disabled and regular class students. Remedial \& Special Education, 7, 33-40.

Chiang, B., Thorpe, H. W., \& Darch, C. B. (1980). Effects of cross-age tutoring on word-recognition performance of learning disabled students. Learning Disability Quarterly, 3, 11-19.

Clark, F. L., Deshler, D. D., Schumaker, J. B., Alley, G. R., \& Warner, M. M. (1984). Visual imagery and self-questioning strategies to improve comprehension of written material. Journal of Learning Disabilities, 17, 145-149.

Condus, M. M., Marshall, K. J., \& Miller, S. R. (1986). Effects of the keyword mnemonic strategy on vocabulary acquisition and maintenance by learning disabled children. Journal of Learning Disabilities, 19, 609-613.

Dahl, P. R. (1979). An experimental program for teaching high speed word recognition and comprehension skills. In J. Button, T. Lovitt, \& T. Rowland (Eds.), Communications research in learning disabilities and mental retardations (pp. 33-65). Baltimore: University Park Press.

Darch, C. , \& Carnine, D. (1986). Teaching content area material to learning disabled students. Exceptional Children, 53, 240-246.

Darch, C., \& Gersten, R. (1986). Direction-setting activities in reading comprehension: A comparison of two approaches. Learning Disability Quarterly, 9, 235-243.

Darch, C., \& Kameenui, E. J. (1987). Teaching LD students critical reading skills: A systematic replication. Learning Disability Quarterly, $10,82-91$.

Davey, B. (1987). Postpassage questions: Task and reader effects on comprehension and metacomprehension processes. Journal of Reading Behavior, 19, 261-282.

Deshler, D. D., \& Graham, S. (1980). Tape recording educational materials for secondary handicapped students. Teaching Exceptional Children, $12,52-54$.

Epstein, L. (1978). The effects of intraclass peer tutoring on the vocabulary development of learning disabled children. Journal of Learning Disabilities, 11, 63-66.

Fayne, H. R., \& Bryant, N. D. (1981). Relative effects of various word synthesis strategies on the phonics achievement of learning disabled youngsters. Journal of Educational Psychology, 73, 616-623.

Fleisher, L. S., \& Jenkins, J. R. (1978). Effects of contextualized and decontextualized practice conditions on word recognition. Learning Disability Quarterly, 1, 39-47.

Fleisher, L. S., \& Jenkins, J. R. (1983). The effect of word- and comprehension-emphasis instruction on reading performance. Learning Disability Quarterly, 6, 146-154.

Freeman, T. J., \& McLaughlin, T. F. (1984). Effects of a taped-words treatment procedure on learning disabled students' sight-word oral reading. Learning Disability Quarterly, 7, 49-54.

Gang, D., \& Poche, C. E. (1982). An effective program to train parents as reading tutors for their children. Education \& Treatment of Children, 5, 211-232.

Gaskins, I., Downer, M., Anderson, R., Cunningham, P., Gaskins, R., Schommer, M., \& Teachers of Benchmark School. (1988). A metacognitive approach to phonics: Using what you know to decode what you don't know. Remedial \& Special Education, 9, 36-41.

Gickling, E. E., \& Armstrong, D. L. (1978). Levels of instructional difficulty as related to on-task behavior, task completion, and comprehension. Journal of Learning Disabilities, 11, 32-39.

Gold, J., \& Fleisher, L. S. (1986). Comprehension breakdown with inductively organized text: Differences between average and disabled readers. Remedial \& Special Education, 7, 26-32.

Graham, S. (1980). Word recognition skills of leaming disabled children and average students. Reading Psychology, 2, 23-33. 
Graham, S. (1983). Selecting reading materials for learning disabled adolescents. Pointer, 27, 18-21.

Graham, S. (1985). Teaching basic academic skills to learning disabled students: A model of the teaching-learning process. Journal of Learning Disabilities, 18, 528-534.

Graham, S., Harris, K. R., \& Sawyer, R. (1987). Composition instruction with learning disabled students: Self-instructional strategy training. Focus on Exceptional Children, 20, 1-11.

Graue, E., Weinstein, T., \& Walberg, H. (1983). School-based home instruction and learning: A quantitative synthesis. Journal of Educational Research, 76, 351-360.

Graves, A. W. (1986). Effects of direct instruction and metacomprehension training on finding main ideas. Learning Disabilities Research, 1, 90-100.

Guthrie, J. T., \& Tyler, S. J. (1978). Cognition and instruction of poor readers. Journal of Reading Behaviors, 10, 57-78.

Hansen, C. (1978). Story retelling used with average and learning disabled readers as a measure of reading comprehension. Learning Disability Quarterly, 1, 62-69.

Harber, J. R. (1983). The effects of illustrations on the reading performance of learning disabled and normal children. Learning Disability Quarterly, 6, 55-60.

Harris, K., Prellor, D., \& Graham, S. (1988, April). Acceptability of cognitive-behavioral and behavioral interventions among classroom teachers. Paper presented at 1988 American Educational Research Association Annual Meeting, New Orleans.

Henderson, A. J., \& Shores, R. E. (1982). How learning disabled students' failure to attend to suffixes affects their oral reading performance. Journal of Learning Disabilities, 15, 178-182.

Holmes, B. C. (1983). The effect of prior knowledge on the question answering of good and poor readers. Journal of Reading Behavior, 15, 1-18.

Holmes, B. C. (1985). The effects of a strategy and sequenced materials on the inferential comprehension of disabled readers. Journal of Learning Disabilities, $18,542-546$.

Idol, L. (1987a). A critical thinking map to improve content area comprehension of poor readers. Remedial \& Special Education, 8, 28-40.

Idol, L. (1987b). Group story mapping: A comprehension strategy for both skilled and unskilled readers. Journal of Learning Disabilities, 20, 196-205.

Idol, L., \& Croll, V. J. (1987). Story-mapping training as a means of improving reading conprehension. Learning Disability Quarterly, 10, 214-229.

Idol-Maestas, L. (1985). Getting ready to read: Guided probing for poor comprehenders. Learning Disability Quarterly, 8, 243-254.

Jenkins, J. R., Barksdale, A., \& Clinton, L. (1978). Improving reading comprehension and oral reading: Generalization across behaviors, settings and time. Journal of Learning Disabilities, 11, 5-15.

Jenkins, J. R., Heliotis, J., Haynes, M., \& Beck, K. (1986). Does passive learning account for disabled readers' comprehension deficits in ordinary reading situations? Learning Disability Quarterly, 9, 69-76.

Jenkins, J. R. Heliotis, J.D., Stein, M. L., \& Haynes, M. C. (1987). Improving reading comprehension by using paragraph restatements. Exceptional Children, 54, 54-59.

Jenkins, J.R., \& Larson, K. (1979). Evaluating error-correction procedures for oral reading. Journal of Special Education, 13, 145-156.

Jenkins, J. R., Larson, K. , \& Fleisher, L. (1983). Effects of error correction on word recognition and reading comprehension. Learning Disability Quarterly, 6, 139-145.

Jenkins, J. R., Mayhall, W. F., Peschka, C. M., \& Jenkins, L. (1974). Comparing small group and tutorial instruction in resource rooms. Exceptional Children, 40, 245-251.

Jorm, A. F. (1977). Effect of word imagery on reading performance as a function of reader ability. Journal of Educational Psychology, 69, 46-54.

Keene, S., \& Davey, B. (1987). Effects of computer-presented text on LD adolescents' reading behaviors. Learning Disability Quarterly, 10, 283-290.
Kirby, K. C., Holborn, S. W., \& Bushby, H. T. (1981). Word game Bingo: A behavioral treatment package for improving textual responding to sight words. Journal of Applied Behavior Analysis, 14, 317-326.

Knowlton, H. E. (1980). Effects of picture fading on two learning disabled students' sight word acquisition. Learning Disability Quarterly, 3, 88-96.

Leinhardt, G., Zigmond, N., \& Cooley, W. W. (1981). Reading instruction and its effects. American Educational Research Journal, 18, 343-361 .

Manis, F. R. (1985). Acquisition of word identification skills in normal and disabled readers. Journal of Educational Psychology, 77, 78-90.

Mastropieri, M. A., Scruggs, T. E., \& Levin, J. R. (1985). Maximizing what exceptional students can learn: A review of research on the keyword method and related mnemonic techniques. Remedial \& Special Education, 6, 39-45.

Mastropieri, M. A., Scruggs, T. E., \& Levin, J. R. (1987). Learning-disabled students' memory for expository prose: Mnemonic versus nonmnemonic pictures. American Educational Research Journal, 24, 505-519.

Mastropieri, M. A., Scruggs, T. E., Levin, J. R., Gaffney, J., \& McLoone, B. (1985). Increasing the vocabulary of learning disabled students using mnemonic instruction. Learning Disability Quarterly, 8, 57-63.

McCormick, S., \& Hill, D. S. (1984). An analysis of the effects of two procedures for increasing disabled readers' inferencing skills. Journal of Educational Research, 77, 219-226.

McKeown, M., \& Beck, I. (1988). Learning vocabulary: Different ways for different goals. Remedial \& Special Education, 9, 42-52.

Miller, C., Miller, L., \& Rosen, L. (1988). Modified reciprocal teaching in a regular classroom. Journal of Experimental Education, 56, 183186.

O'Shea, L. J., Munson, S. M., \& O'Shea, D. J. (1984). Error correction in oral reading: Evaluating the effectiveness of three procedures. Education \& Treatment of Children, 7, 203-214.

O'Shea, L. J., \& Sindelar, P. T. (1983). The effects of segmenting written discourse on the reading comprehension of low- and high-performance readers. Reading Research Quarterly, 18, 458-465.

O'Shea, L. J., Sindelar, P. T., \& O'Shea, D. J. (1987). The effects of repeated readings and attentional cues on the reading fluency and comprehension of learning disabled readers. Learning Disabilities Research, 2, 103-109.

Palinscar, A. S., \& Brown, A. L. (1984). Reciprocal teaching of comprehension-fostering and comprehension-monitoring activities. Cognition \& Instruction, 1, 117-175.

Palinscar, A. S., \& Brown, A. L. (1988). Teaching and practicing thinking skills to promote comprehension in the context of group problem-solving. Remedial \& Special Education, 9, 53-59.

Pany, D., \& Jenkins, J. R. (1978). Learning word meanings: A comparison of instructional procedures. Learning Disability Quarterly, 1, 21-32.

Pany, D., Jenkins, J. R., \& Schreck, J. (1982). Vocabulary instruction: Effects on word knowledge and reading comprehension. Learning Disability Quarterly, 5, 202-215.

Perfetti, C. A. (1986). Continuities in reading acquisition, reading skill, and reading disability. Remedial \& Special Education, 7, 11-21.

Pflaum, S. W., \& Pascarella, E. T. (1980). Interactive effects of prior reading achievement and training in context on the reading of learningdisabled children. Reading Research Quarterly, 16, 138-158.

Pflaum, S. W., Pascarella, E. T., Auer, C., Augustyn, L., \& Boswick, M. (1982). Differential effects of four comprehension-facilitating conditions on LD and normal elementary-school readers. Learning Disability Quarterly, 5, 106-116.

Pressley, M., Johnson, C., Symons, S., McGoldrick, J., \& Kurita, J. (in press). Reading comprehension strategies that can be taught efficiently. Elementary School Journal.

Rashotte, C: A., \& Torgesen, J. K. (1985). Repeated reading and reading fluency in learning disabled children. Reading Research Quarterly, 20, 180-188.

Roberts, M., \& Smith, D. D. (1980). The relationship among correct and error oral reading rates and comprehension. Learning Disability $Q u a r$ terly, 3, 54-64. 
Rose, M. C., Cundick, B. P., \& Higbee, K. L. (1983). Verbal rehearsal and visual imagery: Mnemonic aids for learning-disabled children. Journal of Learning Disabilities, 16, 352-354.

Rose, T. L. (1984). The effects of two prepractice procedures on oral reading. Journal of Learning Disabilities, 17, 544-548.

Rose, T. L. (1986). Effects of illustrations on reading comprehension of learning disabled students. Journal of Learning Disabilities, 19, 542 544.

Rose, T. L., \& Beattie, J. R. (1986). Relative effects of teacher-directed and taped previewing on oral reading. Learning Disability Quarterly, 9, 193-199.

Rose, T. L., McEntire, E., \& Dowdy, C. (1982). Effects of two error-correction procedures on oral reading. Learning Disability Quarterly, 5, 101-105.

Rose, T. L., \& Robinson, H. H. (1984). Effects of illustrations on learning disabled students' reading performance. Learning Disability Quarterly, $7,165-171$.

Rose, T. L., \& Sherry, L. (1984). Relative effects of two previewing procedures on LD adolescents' oral reading performance. Learning Disability Quarterly, 7, 39-44.

Rosenberg, M. S. (1986). Error-correction during oral reading: A comparison of three techniques. Learning Disability Quarterly, 9, 182-192.

Sachs, A. (1983). The effects of three prereading activities on learning disabled students' reading comprehension. Learning Disability Quarterly, 6, 248-251.

Sachs, A. (1984a). Accessing scripts before reading the story. Learning Disability Quarterly, 7, 226-228.

Sachs, A. (1984b). The effects of previewing activities on oral reading miscues. Remedial \& Special Education, 5, 45-49.

Salend, S., \& Nowak, M. (1988). Effects of peer-previewing on LD students' oral reading skills. Learning Disability Quarterly, 11,47-54.

Schumaker, J. B., Deshler, D. D., Alley, G. R., Warner, M. M., \& Denton, P. H. (1982). Multipass: A learning strategy for improving reading comprehension. Learning Disability Quarterly, 5, 295-304.

Schumaker, J. B., Deshler, D. D., \& Denton, P. H. (1984). An integrated system for providing content to learning disabled adolescents using an audio-taped format. In W. Cruickshank \& J. Kliebhan (Eds.), Early adolescence to early adulthood (pp. 79-107.) Syracuse, NY: Syracuse University Press.

Shake, M. C. (1986). Teacher interruptions during oral reading instruction: Self-monitoring as an impetus for change in corrective feedback. Remedial \& Special Education, 7, 18-24.

Short, E. J., \& Ryan, E. B. (1984). Metacognitive differences between skilled and less skilled readers: Remediating deficits through story grammar and attribution training. Journal of Educational Psychology, $76,225-234$.
Sindelar, P. T. (1982). The effects of cross-aged tutoring on the comprehension skills of remedial reading students. Journal of Special Education, 16, 199-206.

Slavin, R., Stevens, R., \& Madden, N. (1988). Accommodating student diversity in reading and writing instruction: A cooperative learning approach. Remedial \& Special Education, 9, 60-66.

Swanson, L. (1981). Modification of comprehension deficits in learning disabled children. Learning Disability Quarterly, 4, 189-201.

Thorpe, H. W., \& Borden, K. S. (1985). The effect of multisensory instruction upon the on-task behaviors and word reading accuracy of learning disabled children. Journal of Learning Disabilities, 18, 279286.

Torgesen, J. K., Dahlem, W. E., \& Greenstein, J. (1987). Using verbatim text recordings to enhance reading comprehension in learning disabled adolescents. Learning Disabilities Focus, 3, 30-38.

Trovato, J. \& \& Bucher, B. (1980). Peer tutoring with or without home-based reinforcement, for reading remediation. Journal of Applied Behavior Analysis, 13, 129-141.

White, C. V., Pascarella, E. T., \& Pflaum, S. W. (1981). Effects of training in sentence construction on the comprehension of learning disabled children. Journal of Educational Psychology, 73, 697-704.

Williams, J. P. (1980). Teaching decoding with an emphasis on phoneme analysis and phoneme blending. Journal of Educational Psychology, $72,1-15$.

Williams, J. P. (1986). Teaching children to identify the main idea of expository texts. Exceptional Children, 53, 163-168.

Willis, J. W., Morris, B., \& Crowder, J. (1972). A remedial reading technique for disabled readers that employs students as behavioral engineers. Psychology in the Schools, 9, 67-70.

Wong, B. Y. L. (1979). Increasing retention of main ideas through questioning strategies. Learning Disability Quarterly, 2, 42-47.

Wong, B. Y. L. (1980). Activating the inactive learner: Use of questions/ prompts to enhance comprehension and retention of implied information in learning disabled children. Learning Disability Quarterly, 3, 29-37.

Wong, B. Y. L. (1982). Strategic behaviors in selecting retrieval cues in gifted, normal achieving and learning-disabled children. Journal of Learning Disabilities, 15, 33-37.

Wong, B. Y. L., \& Jones, W. (1982). Increasing metacomprehension in learning disabled and normally achieving students through self-questioning training. Learning Disability Quarterly, 5, 228-239.

Wong, B. Y. L., Wong, R., \& Le Mare, L. (1982). The effects of knowledge of criterion task on comprehension and recall in normal achieving and learning disabled children. Journal of Educational Research, 76, 119-126.

\section{Professional update \\ NEW JOURNAL}

The National Education Association has introduced a journal of discussion and debate. Entitled Issues '89, it is published 10 times a year, monthly except July and August and bi-weekly in October. It features commentary on the education challenges facing the nation.
A sample of the questions addressed is: What is the emerging movement for national teacher certification all aboutand how might it affect teachers? What kind of power should teachers have in making decisions that affect learning?

This journal is visually appealing and well designed. It is mailed to all NEA members, and included within membership dues. For more information, write: NEA, 1201 16th St., N.W., Washington, DC 20036. 